Supporting Information for:

\title{
Paclitaxel-Promoted Supramolecular Polymerization of Peptide Conjugates
}

\author{
Hao $\mathrm{Su}^{1}$, Weijie Zhang ${ }^{1,2}$, Han Wang ${ }^{1}$, Feihu Wang ${ }^{1}$, and Honggang Cui ${ }^{1,3,4 *}$
}

\begin{abstract}
Affiliations:
${ }^{1}$ Department of Chemical and Biomolecular Engineering, and Institute for NanoBioTechnology, The Johns Hopkins University, 3400 North Charles Street, Baltimore, Maryland 21218, United States.

${ }^{2}$ Department of Oncology, The First Affiliated Hospital of Zhengzhou University, 1 Jianshe Eastern Road, Zhengzhou 450052, Henan, China.

${ }^{3}$ Center for Nanomedicine, The Wilmer Eye Institute, Johns Hopkins University School of Medicine, 400 North Broadway, Baltimore, Maryland 21231, United States.

${ }^{4}$ Department of Oncology and Sidney Kimmel Comprehensive Cancer Center, Johns Hopkins University School of Medicine, Baltimore, Maryland 21205, United States.

*Correspondence to: hcui6@jhu.edu
\end{abstract}


S1. Molecular synthesis and characterization

S1.1 Chemicals and reagents

All amino acids and Rink Amide MBHA Resin were purchased from Advanced Automated Peptide Protein Technologies (AAPPTEC, Louisville, KY, USA). Paclitaxel (PTX) was purchased from Ava Chem Scientific (San Antonio, TX) and chemically modified to PTX-buss-Pyr ${ }^{1,2}$ in our lab. $\mathrm{mPEG}_{4}-\mathrm{CH}_{2} \mathrm{CH}_{2} \mathrm{COOH}\left(\mathrm{OEG}_{5}-\mathrm{COOH}\right)$ was sourced from PurePEG LLC (San Diego, CA, USA). All other reagents and solvents were purchased from VWR (Radnor, PA, USA) or Sigma-Aldrich (St. Louis, MO).

\section{S1.2 Synthesis of peptide precursor}

Peptide auxiliary was synthesized using standard 9-fluorenylmethoxycarbonyl (Fmoc) solid phase peptide synthesis technique on the Rink Amide MBHA resins. Figure S1 shows a representative synthetic procedures of peptide precursor Cys(Ac)-GNNQQKoEgKoegKoegKoeg. All amino acids were sequentially added onto the resins with amino acids/HBTU/DIEA at a ratio of 4:4:6 (molar equivalents to resin) in DMF for $2 \mathrm{~h}$ after Fmoc removal by a 20\% 4-methylpiperidine in DMF solution for 15 minutes (repeat once). $\mathrm{OEG}_{5}-\mathrm{COOH}$ was conjugated to the side chain of lysine (Mtt) by adding $\mathrm{OEG}_{5}-\mathrm{COOH} / \mathrm{HBTU} / \mathrm{DIEA}$ at a ratio of 2:2:3 for $6 \mathrm{~h}$ (molar equivalents to free amine groups) after Mtt deprotection by 3\% TFA $/ 5 \%$ TIS/92\% DCM for 5 min (repeat 5-6 times). Acetylation was performed after Fmoc removal by adding 20\% acetic anhydride/DMF solution with $100 \mu \mathrm{L}$ DIEA for $15 \mathrm{~min}$, repeating twice. Peptides were cleaved from the resin using a mixture of TFA/TIS/ $\mathrm{H}_{2} \mathrm{O}$ at a ratio of $95: 2.5: 2.5$ for $3 \mathrm{~h}$. The free thiol group on the cysteine remained for further conjugation of PTX with peptides by disulfide formation. The cleaved peptide TFA solution was concentrated and precipitated in cold diethyl ether to give crude peptide precipitates. The peptide precursor Cys(Ac)-GNNQQKoegKoegKoeg was also synthesized using similar procedures.

The vacuum-dried crude peptides were diluted by water/acetonitrile containing $0.1 \%$ TFA at a ratio of $9 / 1$ and filtered by $0.45 \mu \mathrm{m}$ PTFE syringe filters. The crude peptide solutions were firstly analyzed by analytical RP-HPLC (a Varian ProStar Model 325 HPLC, Agilent Technologies, Santa Clara, CA) using a Varian Pursuit XRs C18 column $(5 \mu \mathrm{m}, 150 \times 4.6 \mathrm{~mm})$ with a flow rate of $1 \mathrm{~mL} / \mathrm{min}$ for $20 \mathrm{mins}$ from $10 \%$ acetonitrile to $70 \%$ acetonitrile and monitored at $220 \mathrm{~nm}$. Subsequently, the peptides were purified by a Varian PLRP-S column ( $100 \AA, 10 \mu \mathrm{m}, 150 \times 25 \mathrm{~mm})$ with a flow rate of $20 \mathrm{~mL} / \mathrm{min}$ for 25 mins from $10 \%$ acetonitrile to $40 \%$ acetonitrile and monitored at $220 \mathrm{~nm}$. Purified fractions were verified by ESI-MS (a Finnigan LDQ Deca ion-trap mass spectrometer, Thermo-Finnigan, Waltham, MA), concentrated by rotary evaporation, and lyophilized by a FreeZone $-105{ }^{\circ} \mathrm{C} 4.5 \mathrm{~L}$ freeze dryer (Labconco, Kansas City, MO). The purified peptides were re-characterized by analytical RP-HPLC (Figure S2 and S4) with a flow rate of $1 \mathrm{~mL} / \mathrm{min}$ initiating from $5 \%$ acetonitrile to $95 \%$ acetonitrile for $15 \mathrm{~min}$, holding for $1 \mathrm{~min}$, and going back to $5 \%$ acetonitrile at 20 mins. 


\section{S1.3 Synthesis of Spheropax (Spax) and Filopax(Fpax)}

To synthesize Spax and Fpax, purified peptide and PTX-buss-Pyr were mixed at a molar ratio of 1:1.2 (PTX-buss-Pyr/peptide) and reacted for 2 days in $\mathrm{N}_{2}$-purged DMSO (Figure S1). ${ }^{1}$ The crude reactions were further diluted with water/acetonitrile containing $0.1 \%$ TFA at a ratio of $6 / 4$ and purified by preparative HPLC at the following conditions: flow rate of $20 \mathrm{~mL} / \mathrm{min}$ for $30 \mathrm{mins}$ from $25 \%$ acetonitrile to $50 \%$ acetonitrile and absorption channel at $237 \mathrm{~nm}$. Purified fractions were verified by ESI-MS, concentrated and lyophilized. The final products were re-characterized by analytical RP-HPLC (Figure S3 and S5), calibrated, aliquoted into cryo-vials and re-lyophilized for future use and storage.

S2. Self-assembly Spax, Fpax, and PTX-promoted supramolecular polymerization of Spax

All the self-assembly experiments were performed by directly dissolving hexafluoroisopropanol (HFIP)-pretreated Spax or PTX/Spax mixtures into Milli-Q water at a Spax concentration of $2 \mathrm{mM}$, and the sample solutions were tuned to neutral $\mathrm{pH}$. The self-assembly of Fpax was promoted using similar procedures. In this protocol, sonication and heating $\left(50{ }^{\circ} \mathrm{C}\right.$ water bath) were applied for 5 min to accelerate the dissolving process. The solutions were aged for at least $12 \mathrm{~h}$ at room temperature before any further studies, except for time-dependent experiments.

\section{S2.1 Conventional transmission electron microscopy (TEM)}

TEM samples were prepared by dropping $7 \mu \mathrm{L}$ sample solution onto a carbon-film-coated copper grid (400 square mesh, Electron Microscopy Sciences, Hatfield, PA, USA), and the excess solution was wicked with a filter paper. Another $7 \mu \mathrm{L}$ of staining solution ( $2 \mathrm{wt} \%$ uranyl acetate aqueous solution) was dropped onto the TEM grid and wicked away after $30 \mathrm{~s}$ as a negative staining agent. The grid was air-dried before imaging, and was then imaged using a FEI Tecnai 12 TWIN Transmission Electron Microscope $(100 \mathrm{kV})$. A SIS Megaview III wide-angle CCD camera was used to acquire the TEM images.

\section{S2.2 Cryogenic (cryo) TEM}

Before sample preparation, lacey carbon film supported TEM copper grids (300 square mesh) were pretreated with plasma air to render the lacey carbon film hydrophilic. Cryo-TEM samples were prepared by dropping $6 \mu \mathrm{L}$ of solution onto the grids (300 square mesh). A thin layer of ice was obtained by blotting and instantly plunging the grid into a liquid ethane reservoir precooled by liquid nitrogen using a Vitrobot. The vitrified samples were kept in a precooled cryo-holder maintained below $-170{ }^{\circ} \mathrm{C}$ by liquid nitrogen, and imaged on the same microscope using a 16 bit $2 \mathrm{~K} \times 2 \mathrm{~K}$ FEI Eagle bottom mount camera. 
S2.3 PTX-promoted supramolecular polymerization of Spax

PTX and Spax were dissolved in HFIP at the concentrations of $4 \mathrm{mM}$ and $2 \mathrm{mM}$, respectively. Various amounts of HFIP-pretreated PTX were added into $200 \mu \mathrm{L}$ Spax stock solution to achieve final molar ratios (PTX/Spax) of 5/100, 10/100, 25/100 and $50 / 100$. The mixtures were left uncapped in the fume hood overnight to air-dry all the HFIP at room temperature and re-dissolved in $200 \mu \mathrm{L}$ Milli-Q water to achieve final Spax concentration of $2 \mathrm{mM}$. The solutions were sonicated in $50{ }^{\circ} \mathrm{C}$ water bath for $5 \mathrm{~min}$ and were centrifuged ( $5000 \mathrm{rpm} \times 3 \mathrm{~min}$ ) to remove excess amount of precipitated PTX. The supernatants were carefully collected and analyzed using HPLC to calibrate the final free PTX concentration in the assemblies with the following conditions: a flow rate of 1 $\mathrm{mL} / \mathrm{min}$ initiating from $5 \%$ acetonitrile to $95 \%$ acetonitrile for $15 \mathrm{~min}$, holding for $1 \mathrm{~min}$, and going back to $5 \%$ acetonitrile at 20 mins; the monitored wavelength was $237 \mathrm{~nm}$. The final calibrated PTX/Spax ratios were 6/100, 11/100, 18/100 and 29/100. The solutions were aged for $12 \mathrm{~h}$ before further experiments. The addition of CPT into Spax solution used the sample protocols as the addition of PTX. The initial molar ratio of CPT/Spax was $1 / 1$ and the final CPT/Spax ratio in the supernatant was $2 / 100$ after removal of excess amount of precipitated CPT.

S2.4 Kinetics of PTX-promoted supramolcular polymerization of Spax

A large volume of sample solution $(1 \mathrm{~mL})$ at an initial PTX/Spax feed ratio of 25/100 was prepared using above-mentioned protocols (see section S2.3). After centrifugation to remove excess PTX, the PTX/Spax ratio in the collected supernatant was 20/100. $100 \mu \mathrm{L}$ of sample was taken out from stock solution at different time points $(1 \mathrm{~h}, 4 \mathrm{~h}, 8 \mathrm{~h}, 12 \mathrm{~h}$, $24 \mathrm{~h}, 36 \mathrm{~h}$ and $72 \mathrm{~h}$ ). TEM imaging and CD measurement were performed and summarized. In addition, two other sample solutions (200 $\mu \mathrm{L}$ for each) at PTX/Spax ratios of 3/100 and 8/100 were also prepared. TEM images at various time points were also collected for samples at PTX/Spax ratios of 3/100, 6/100 and 8/100, which were summarized in Figure S10.

\section{S2.5 Circular dichroism (CD) spectroscopy measurement}

Stock solutions $(2 \mathrm{mM})$ were instantly diluted to $100 \mu \mathrm{M}$ prior to each measurement. CD spectra were recorded on a Jasco J-710 spectropolarimeter (JASCO, Easton, MD, USA) using a $1 \mathrm{~mm}$ path length quartz UV-Vis absorption cell (Thermo Fisher Scientific, Pittsburgh, PA, USA). Three repeated scans were obtained from 190 to $400 \mathrm{~nm}$, averaged and then normalized with respect to the sample concentration and path length. The background spectrum of the water was acquired and subtracted from the sample spectra. 


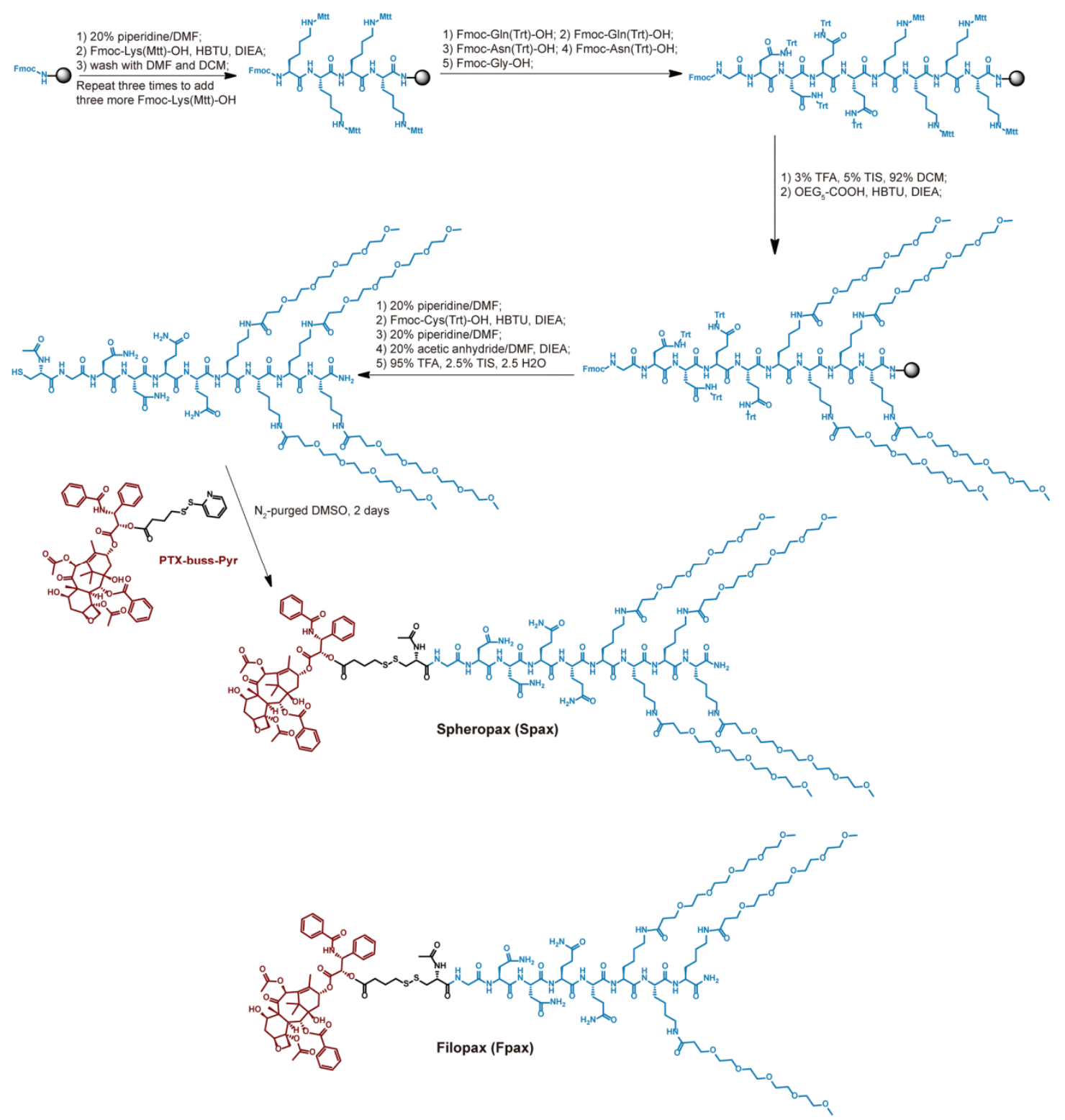

Figure S1. Chemical synthesis of peptide precursors using standard Fmoc solid phase peptide synthesis techniques and synthesis of Spax and Fpax by reacting the peptide auxiliary with PTX-buss-Pyr in DMSO. 

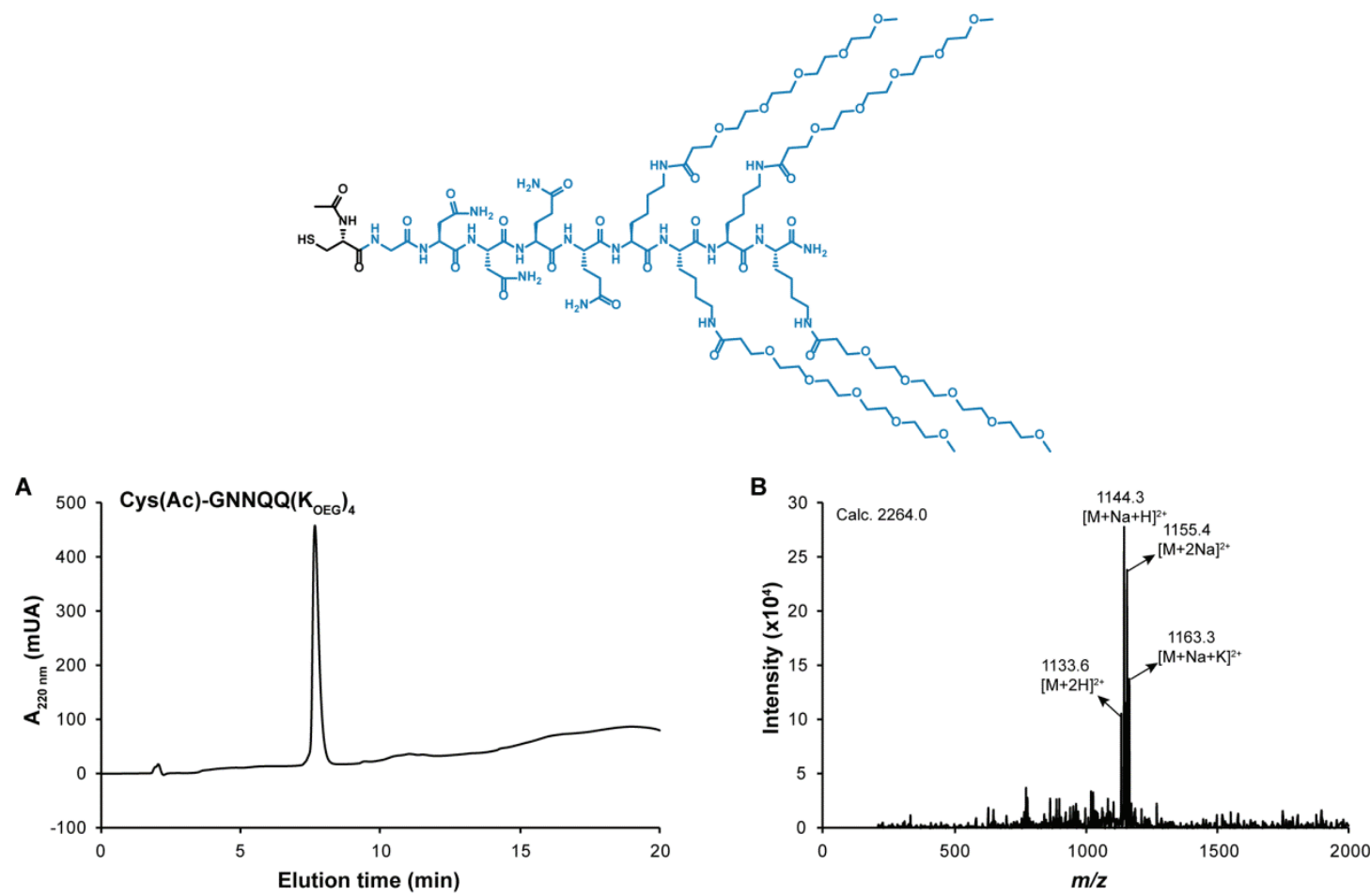

Figure S2. Chemical structure, analytical RP-HPLC and ESI-MS spectra of peptide precursor Cys(Ac)-GNNQQ(KoEG)4 (A and B). The peaks at 1133.6, 1144.3, 1155.4 and 1163.3 correspond to $[\mathrm{M}+2 \mathrm{H}]^{2+}, \quad[\mathrm{M}+\mathrm{Na}+\mathrm{H}]^{2+}, \quad[\mathrm{M}+2 \mathrm{Na}]^{2+}$ and $[\mathrm{M}+\mathrm{Na}+\mathrm{K}]^{2+}$, respectively. 


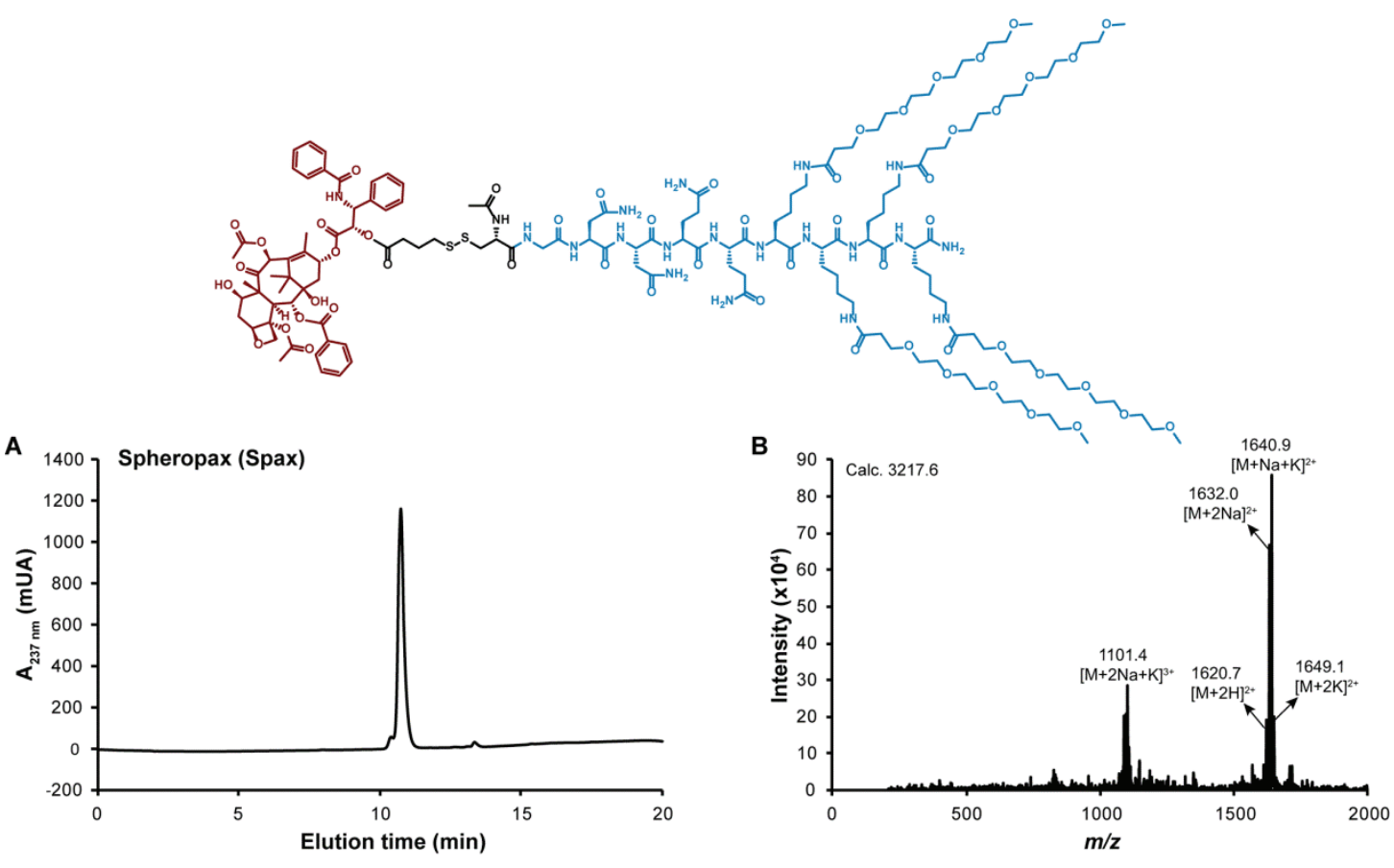

Figure S3. Chemical structure, analytical RP-HPLC and ESI-MS spectra of Spax (A and B). The peaks at $1101.4,1620.7,1632.0,1640.9$ and 1649.1 correspond to $[\mathrm{M}+2 \mathrm{Na}+\mathrm{K}]^{3+}$, $[\mathrm{M}+2 \mathrm{H}]^{2+},[\mathrm{M}+2 \mathrm{Na}]^{2+},[\mathrm{M}+\mathrm{Na}+\mathrm{K}]^{2+}$ and $[\mathrm{M}+2 \mathrm{~K}]^{2+}$, respectively. 


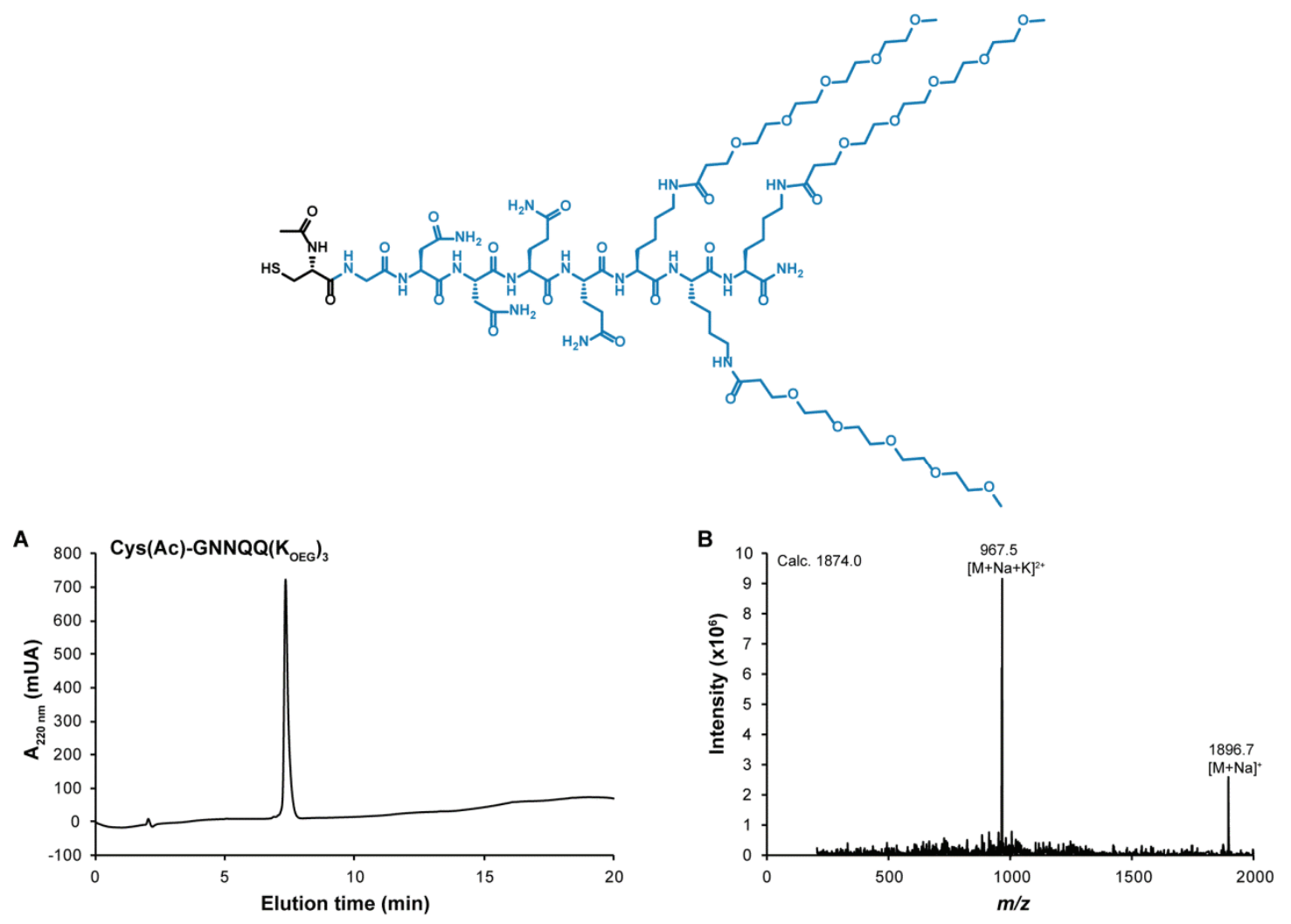

Figure S4. Chemical structure, analytical RP-HPLC and ESI-MS spectra of peptide precursor Cys(Ac)-GNNQQ(Koeg)3 (A and B). The peaks at 967.5 and 1896.7 correspond to $[\mathrm{M}+\mathrm{Na}+\mathrm{K}]^{2+}$ and $[\mathrm{M}+\mathrm{Na}]^{+}$, respectively. 


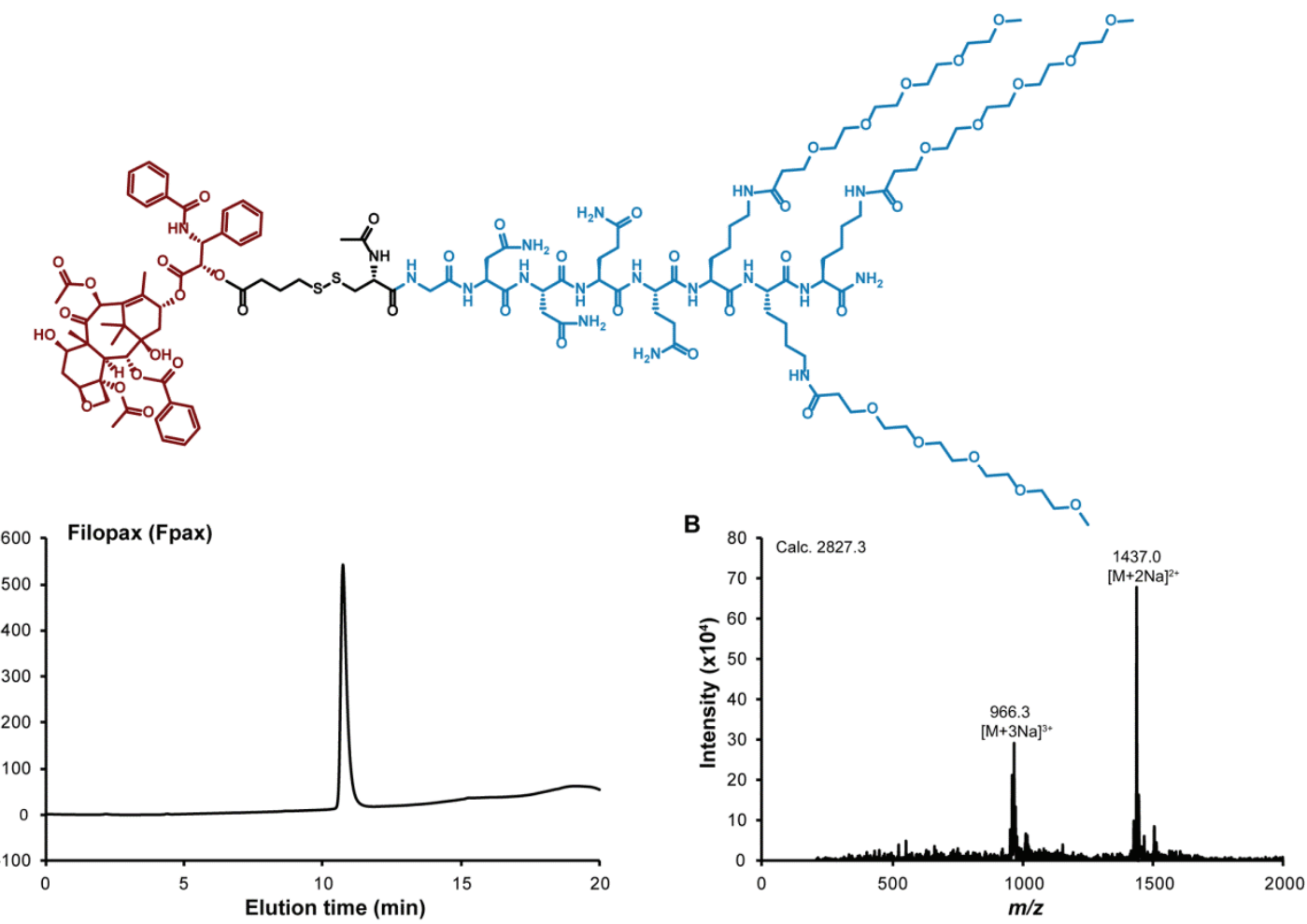

Figure S5. Chemical structure, analytical RP-HPLC and ESI-MS spectra of Fpax (A and B). The peaks at 966.3 and 1437.0 correspond to $[\mathrm{M}+3 \mathrm{Na}]^{3+}$ and $[\mathrm{M}+2 \mathrm{Na}]^{2+}$, respectively. 


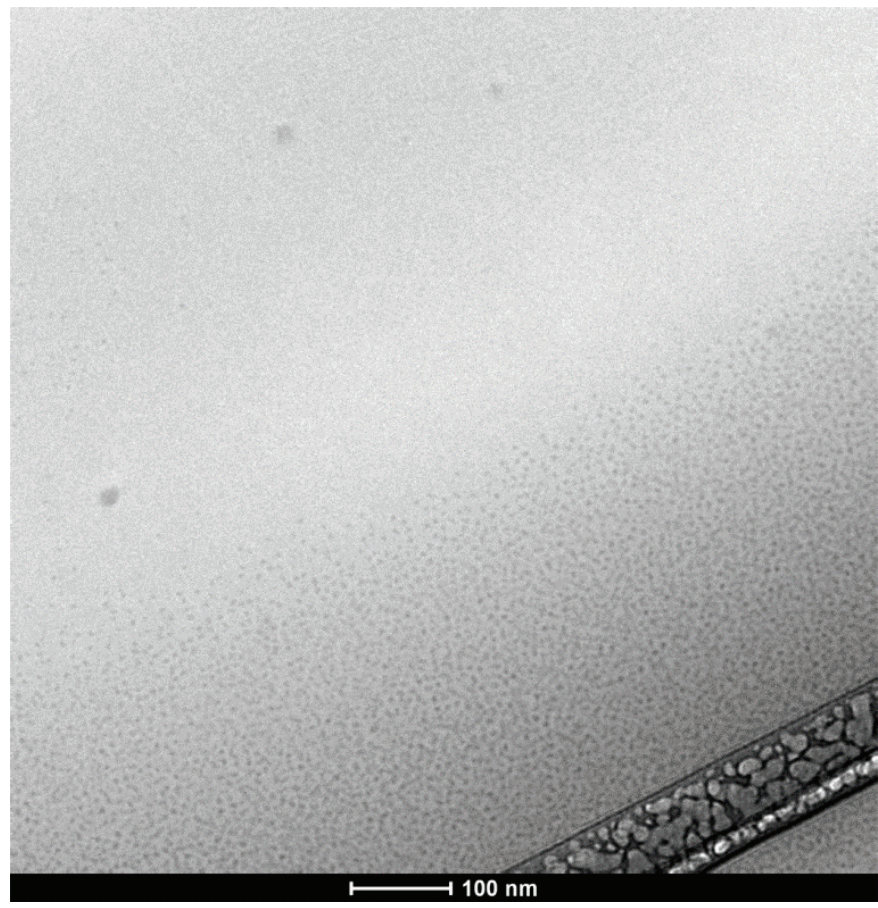

Figure S6. Additional cryo-TEM images of spheres formed by Spax in aqueous solution at a concentration of $2 \mathrm{mM}$ (same sample as that in Figure 1B). 

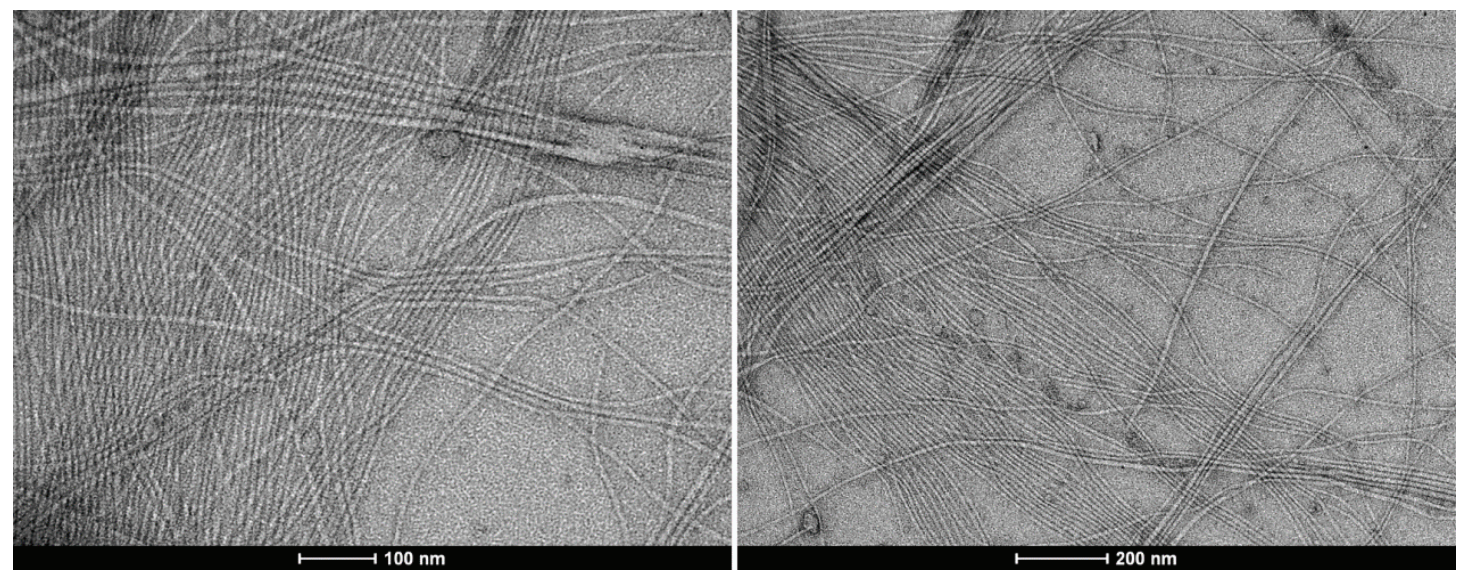

Figure S7. Additional TEM images of filaments formed by PTX-promoted supramolecular polymerization of Spax in aqueous solution (same sample as that in Figure 1E). 


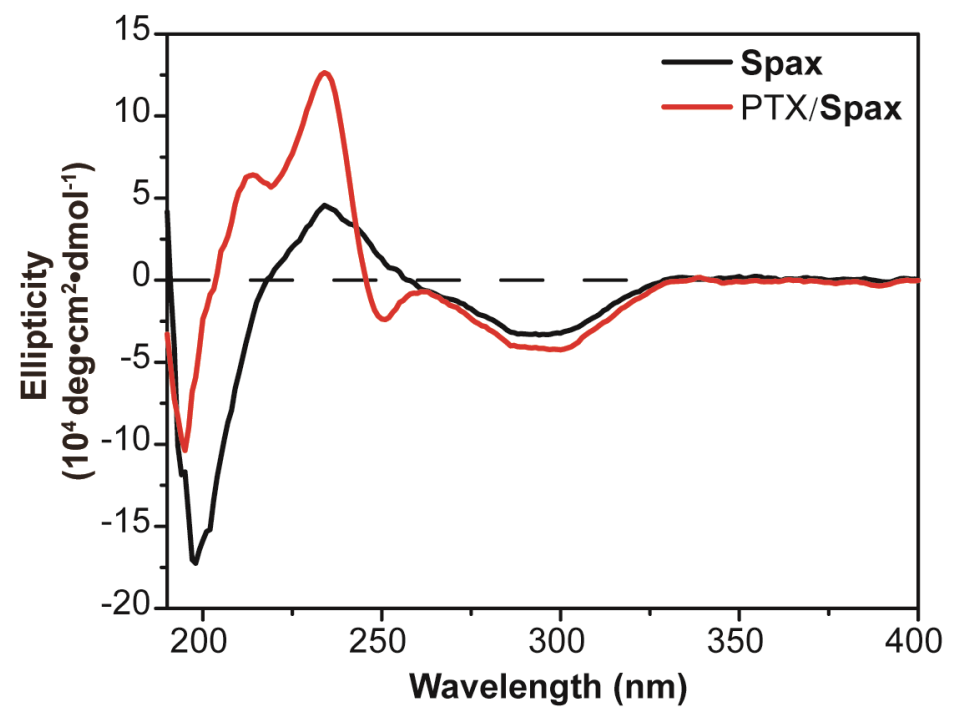

Figure S8. CD spectra of Spax (spheres, black curve) and PTX/ Spax (filaments, red curve). Sample solutions are at a Spax concentration of $2 \mathrm{mM}$, and the PTX/Spax ratio is 18/100. Samples were measured after aging for $12 \mathrm{~h}$ at room temperature and were instantly diluted to $100 \mu \mathrm{M}$ prior to each measurement. Spax has a broad positive signal at $234 \mathrm{~nm}$ and a broad negative peak at $295 \mathrm{~nm}$, which attributes to the $\mathrm{n}-\pi^{*}$ and $\pi-\pi^{*}$ transitions of PTX chromophores associated with different asymmetric centers, respectively. The negative peak at $198 \mathrm{~nm}$ indicates the random coil conformation of peptide auxiliaries. The CD signal is strongly magnified after PTX-promoted supramolecular polymerization of Spax, which formed filamentous structures. The negative peak at $295 \mathrm{~nm}$ with a shoulder around $251 \mathrm{~nm}$, and the strong positive peak at $234 \mathrm{~nm}$ with a shoulder at $212 \mathrm{~nm}$ indicate that PTX molecules in the filaments aligned in a more ordered fashion than those in spheres. Additionally, no hydrogen bonding absorption is observed, which may be present but is overwhelmed by the broad positive signal around $234 \mathrm{~nm}$. 


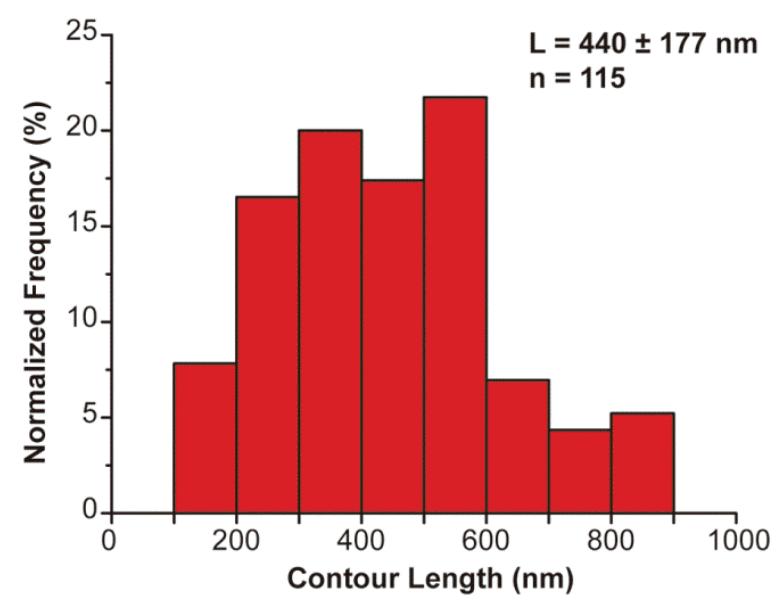

Figure S9. Contour length distribution of short filaments at a PTX/Spax ratio of 11/100 (TEM image in Figure 2B). The length of filaments is $440 \pm 177 \mathrm{~nm}(\mathrm{n}=115)$, while filaments in Figure 2C (PTX/Spax ratio of 29/100) are over $1 \mu \mathrm{m}$. 


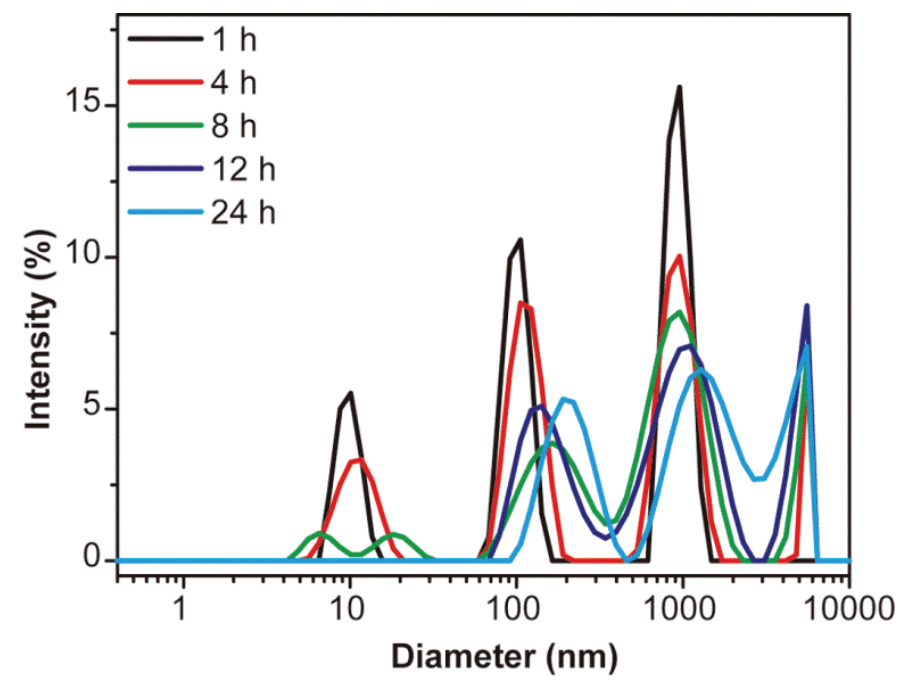

Figure S10. Time-dependent dynamic light scattering (DLS) study of a Spax aqueous solution at a PTX/Spax ratio of 20/100 after aging for $1 \mathrm{~h}, 4 \mathrm{~h}, 8 \mathrm{~h}, 12 \mathrm{~h}$ and $24 \mathrm{~h}$. The results showed an increased trend in size with the increase of incubation time, and no peaks of small aggregates around $10 \mathrm{~nm}$ were observed after $12 \mathrm{~h}$. 

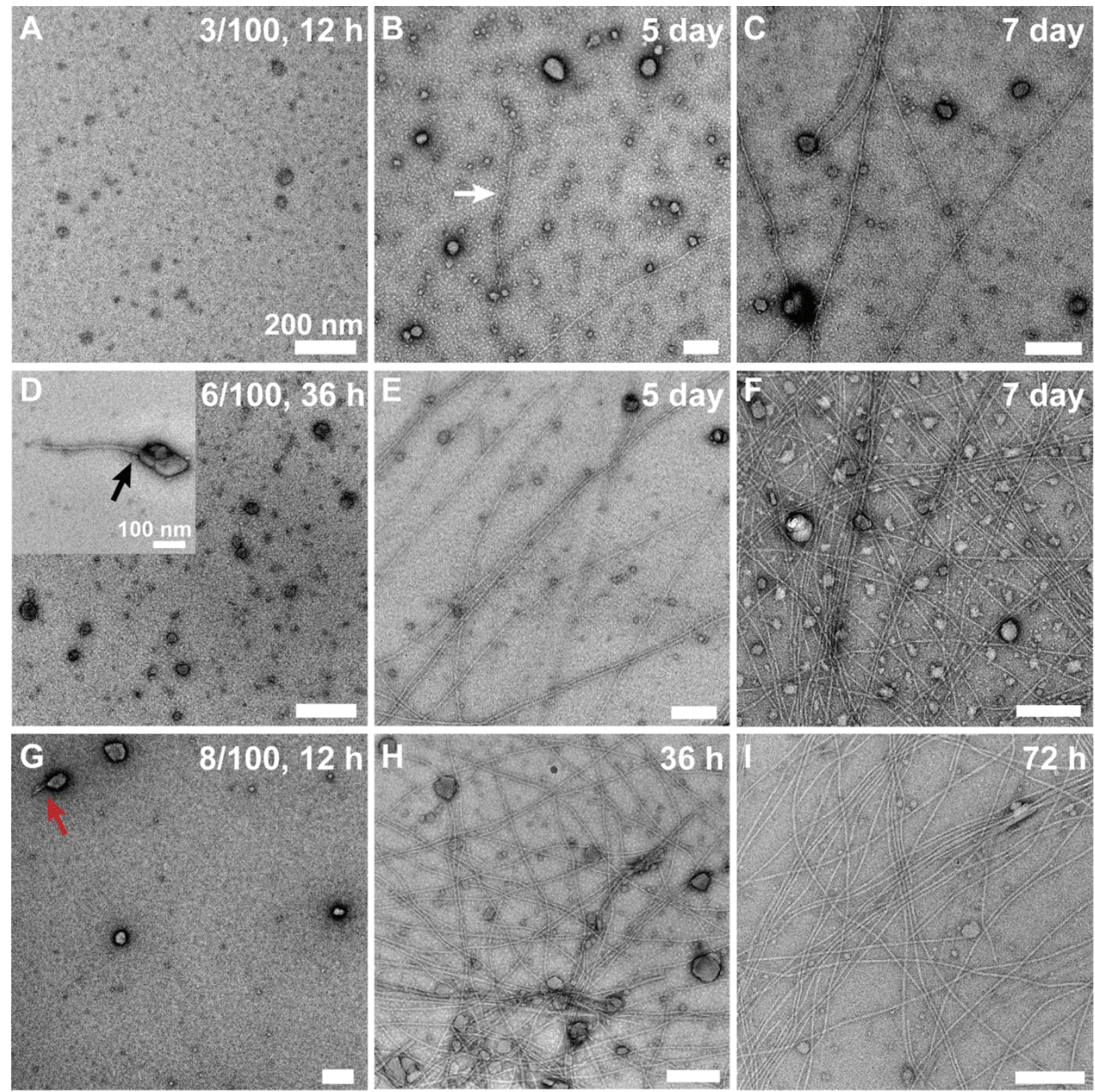

Figure S11. Kinetics of PTX-promoted supramolecular polymerization of Spax at various PTX/Spax ratios. All scale bars are $200 \mathrm{~nm}$ as labeled in A, except the inserted figure in D. A - C are time-dependent TEM images of sample solution at a PTX/Spax ratio of $3 / 100$, which presents spheres of various sizes even up to 7 days with few short fibers (pointed out by white arrow) observed starting from day 5. D $-\mathbf{F}$ are images at a PTX/Spax ratio of 6/100, and a TEM image at $12 \mathrm{~h}$ is shown in Figure 2A. Inserted image in $\mathbf{D}$ shows supramolecular growth of filaments from spheres (pointed out by black arrow). After aging for 5 and 7 days, more and more filaments form, but still many spheres exist in the solution. $\mathbf{G}-\mathbf{I}$ are images at a PTX/Spax ratio of 8/100. Spheres are the dominate structure at $12 \mathrm{~h}$, and filament-branching out from a sphere (pointed out by red arrow) is also observed. More filaments form with time and become the dominate structure at $72 \mathrm{~h}$. All these results lead us to propose the assembly mechanism that monomers form spherical assemblies, which will latterly grow into filaments by PTX-promoted supramolecular polymerization and elongation. Additionally, increasing 
the ratio of PTX (promoter) will accelerate the elongation kinetics and formation of filaments. 

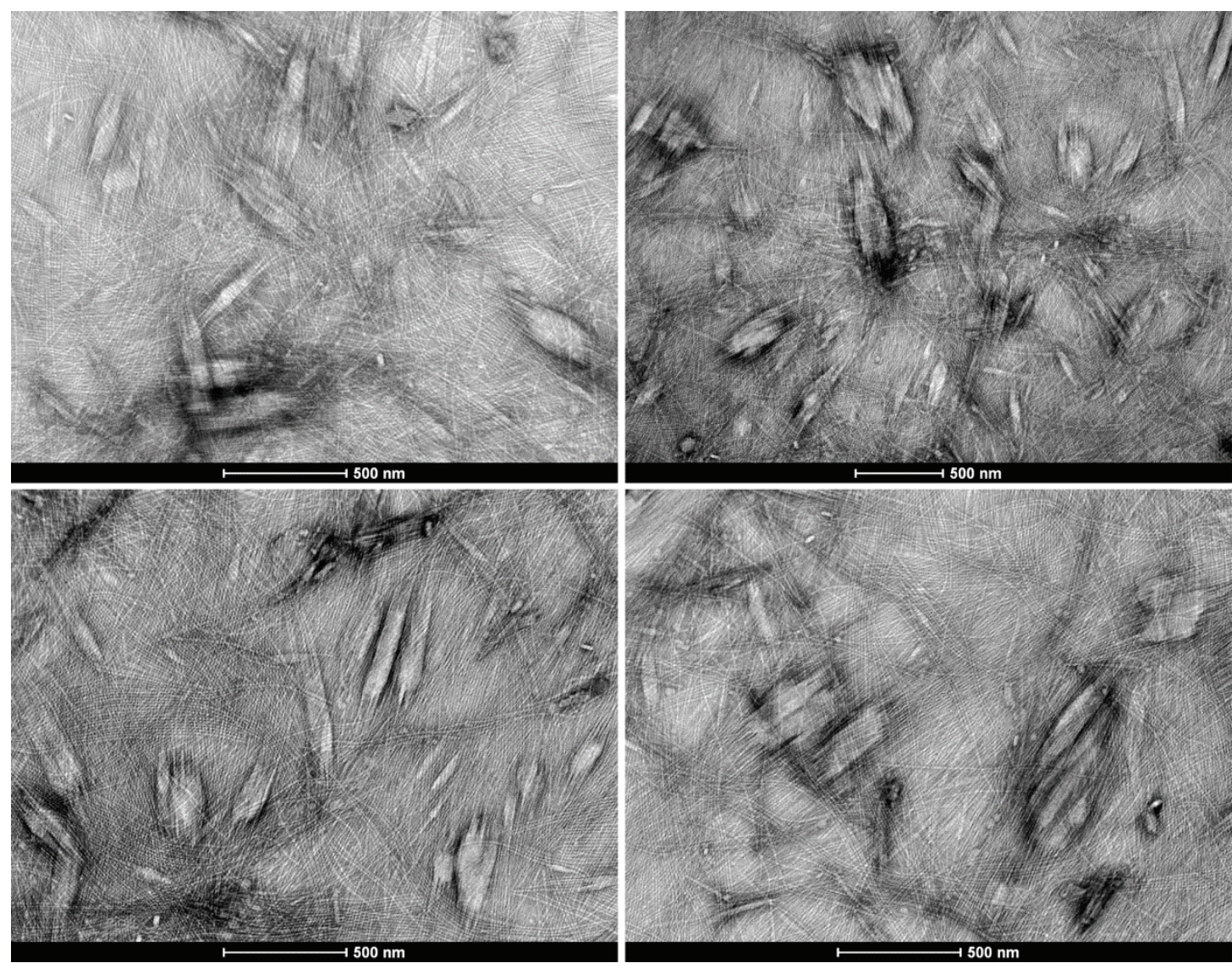

Figure S12. Additional low-magnification TEM images of "brush" morphologies formed by a PTX/Spax ratio of 29/100 after aging for 5 days.

\section{Reference:}

S1 Lin, R.; Cheetham, A. G.; Zhang, P. C.; Lin, Y. A.; Cui, H. G. Chem Commun 2013, 49, 4968.

S2 Cheetham, A. G.; Zhang, P.; Lin, Y. A.; Lin, R.; Cui, H. J Mater Chem B 2014, 2, 7316. 